\title{
Probing Thai freshmen Science Students' Conceptions of Heat and Temperature Using Open-ended questions: A case study
}

\author{
Choksin Tanahoung ${ }^{1, *}$, Ratchapak Chitaree ${ }^{2}$, Chernchok Soankwan ${ }^{2}$ \\ ${ }^{1}$ Department of Physics, Faculty of Science, Ubon Ratchathani University, 85 Sathollmark Road, \\ Warinchamrap, Ubon Ratchathani 34190, Thailand \\ ${ }^{2}$ Physics Education Network of Thailand, Department of Physics, Faculty of Science, Mahidol University, Rama \\ 6 Road, Ratchathevi, Bangkok 10400, Thailand
}

Received 03 September 2010 - Accepted 19 September 2010

\begin{abstract}
The purpose of this study was to investigate the alternative conceptions held by Thai first year science students. A total of 334 first year science students have been tested before the regular first year university instruction on the thermal physics topic began. The first open-ended question for investigating students' conceptions on term temperature, heat, latent heat, specific heat capacity and thermal equilibrium. The second open-ended question for investigating level of students' conceptions of heat conduction. Students' conceptions in each concept were identified into different categories and levels of understanding. The study showed that students' written responses have some common specific misconceptions and different levels of understandings. Most students were unable to offer a correct reason for their answers. The results of this study may imply the teaching style in Thai high schools that may be problematic. In addition, the students' misconceptions found could be used as a guide for developing proper teaching methods on the introductory physics course especially in the topic of thermal physics.
\end{abstract}

Key words: Conceptions, Heat and Temperature, Open-Ended Question

\section{Introduction}

Over several decades, science educators have studied student misconceptions, often termed alternative conceptions which are non-congruent with current scientific understandings; see for example Confrey (1990) and Duit and Treagust (1998). Such studies have led to learning and teaching environments within the constructivist framework aiming to support conceptual change. A critical requirement is that teachers should be able to gauge reliably what conceptions their students hold. Strategies generally used in schools include talking with small groups of students, or asking them to write explanations (Ali, 2002; Geraedts \& Boersma, 2006). However, in higher education and for comparative studies, conceptual surveys seem to have become the instrument of first choice (McDermott \& Redish, 1999), and we note that some of the more widely used conceptual surveys have been translated into several languages, facilitating international dialogues on students' conceptions (Evaluation Instruments, 2010). A key feature is for teachers to first gauge what students' conceptions are. Strategies such as questioning a small group of students or asking students to write explanations are often used within schools. Open-ended questions and drawings provide much and extensive information about misconceptions (White \& Gunstone, 1992;

\footnotetext{
*Corresponding author: Phone: +6645353401 press 4563, ISSN: 1306-3049, C2010 
Ayas, 1993). Open-ended questions provided the researchers both qualitative and quantitative data and also answers were labeled as understanding, misunderstanding, no understanding and no response. (Abraham, Grzybowski, Renner, \& Marek, 1992; Abraham, Williamson, \& Westbrook, 1994).

The area of heat and temperature is important at an introductory level, because it underpins physics and chemistry. It relates to everyday, tangible ideas and is covered across several years of instruction in both high school and university education. This paper describes a study of students' conceptions of thermal physics.

We investigated Thai freshmen science students' conceptions using open-ended written questions. We investigate these ideas that can be taught and what effect this has on various outcomes: the understanding of the ideas themselves, the ability to carry out open-ended questions or the use of those ideas in developing a scientific literacy. This study concerns students' conceptions with open-ended investigations.

The research questions are as follows.

1. What are Thai freshmen science students' conceptions about temperature, heat, latent heat, specific heat capacity, and thermal equilibrium?

2. What are levels of Thai freshmen science students' understandings of heat conduction?

\section{Theoretical Framework}

\section{Students' understandings of thermal concepts}

Many researchers are interested in studying students' misconception of heat and temperature (Sozbilir, 2003). At a basic level, the obvious problem was that students were unable to distinguish clearly between the concepts of heat and temperature (Carlton, 2000; Jara-Guerrero, 1993; Yeo \& Zadnik, 2001). Paik, Cho and Go (2007) studied 4 to 11 year-old Korean students' conceptual understandings of heat and temperature and found that most students did not have clear concepts of thermal equilibrium. Luera, Otto and Zitzewitz (2006) used the Thermal Concept Evaluation test (TCE) as pre- and post-tests to identify students' misconceptions regarding heat and temperature concepts, focusing on those that were useful for designing teaching methods. At a higher level, Harrison, Grayson and Treagust (1999) found that heat and internal energy were confusing for high school students as well as undergraduate students (Lewis \& Linn, 2003; Niaz, 2006). Jasien and Oberem (2002) found that science students and K-12 teachers were lacking in background knowledge of thermal equilibrium, specific heat, and heat capacity. Jonstone, Macdodald and Webb (1997) and Thomas and Schwenz (1998) investigated the conceptual difficulties experienced by pupils studying chemical equilibrium.

\section{Knowledge Background of Thai high school Students}

In Thailand, the Institute for the Promotion of Teaching Science and Technology (IPST) plays an important role in the teaching of science. Based on the 2001 National Curricula in Thailand, the curriculum for Thai high schools is controlled by the IPST. The curricula has been reformed with the intent to improve students' knowledge, thinking process, inquiry thinking skill, problem solving skill, ability of scientific communication, ability of application and scientific attitude (Ministry of Education [MOE], 2001). In thermal physics, the topics covered in grade 11 physics are heat and temperature, change of phase, specific heat capacity, thermal expansion, heat transfer, Boyle 's law, Charles' law, Louis Gay-Lussac' s law and kinetic theory of gases. Classroom instruction has been reorganized to facilitate students to construct their knowledge themselves and apply their knowledge to explain phenomena in everyday life. Concept map about thermal physics for teaching in grad 11 Thai high schools are presented in Figure 1. 


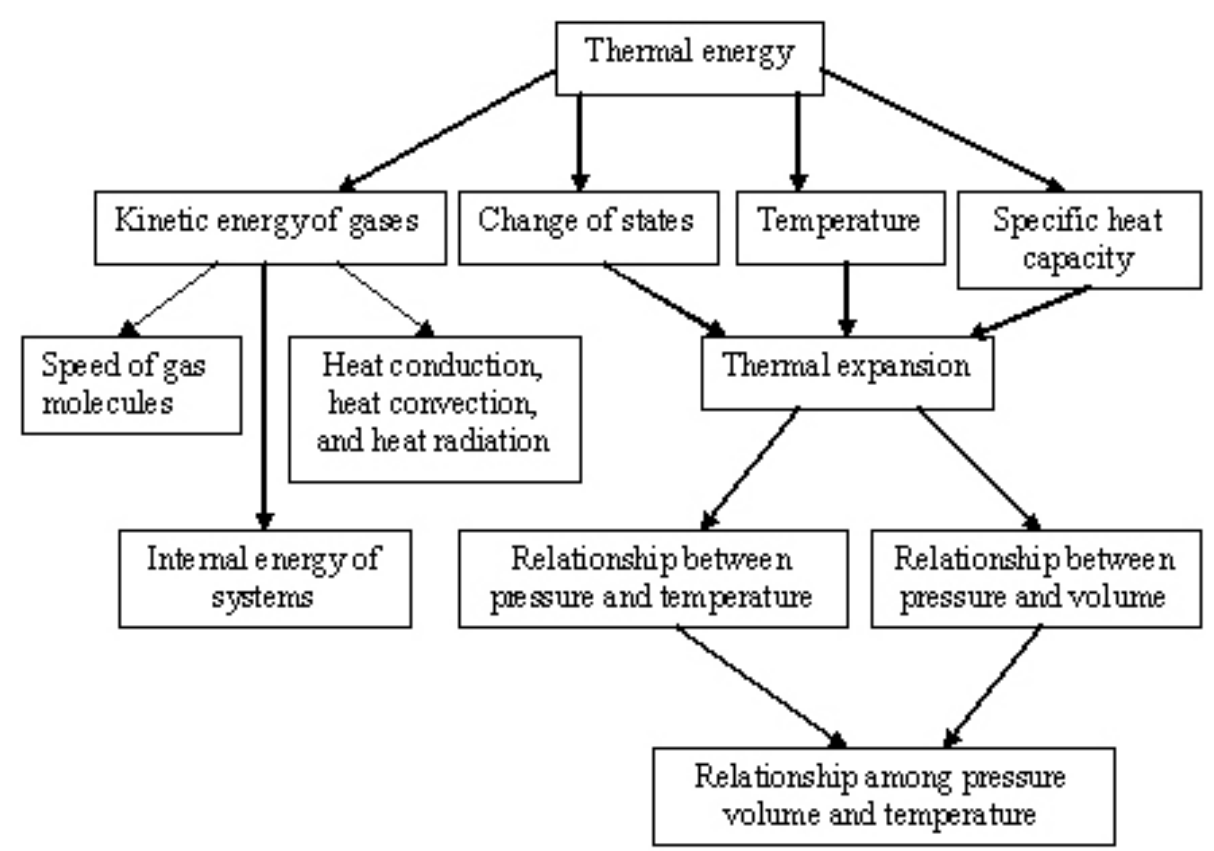

Figure 1. Concept map of Thermal physics for $11 \operatorname{grad}$ Thai students

\section{Methods}

\section{Participants}

The sample was drawn from first year physics courses during the first semester. A total of 334 first year science students have been tested during they participated in Pre-Science Academic Camp before introductory physics instruction began. The data were analyzed to classify alternative conceptions for considering students background knowledge.

\section{The open-ended questions}

There are two open-ended questions to explore students' alternative conceptions on thermal physics. The two questions were used to probe students' understanding at different levels. The first question is a question about words that required students to define or explain the words. The second question is conceptual question that required students integrate and apply concepts to response this question. The two open-ended questions are as follows:

Question 1. What are your understanding about temperature, heat, latent heat, specific heat capacity, and thermal equilibrium? Do you know these concepts? If yes or no: give the responses.

Question 2. Two objects: a piece of metal and a piece of wood, are kept inside a room for a long time (room temperature is $25{ }^{\circ} \mathrm{C}$ ). Which object feels the coldest when you touch it? Please explain your reason.

The two open-ended written questions were administered to a sample of 334 first year students. Students' responses on the two questions were collected and analyzed into types of conceptions and levels of understandings. 


\section{Results and Discussion}

For data collecting and analysis from the two open-ended questions, the first openended question was used to find understanding about the words. The second open-ended question was to classify students' understandings into different levels.

\section{Analysis of the students' conceptions of temperature}

Temperature refers to measure of the average translational kinetic energy per molecule in a substance (MOE, 2001). All students' responses were classified into category of conceptions.

The students' conceptions of temperature were classified into seven categories that are presented in Table 1. The students' responses in each category were 29, 35, 1, 7, 15, 4, and $3 \%$ respectively. The percentage of students in category 2 was the highest $(35 \%)$ followed by category $1(29 \%)$ and category $5(15 \%)$. There was only $1 \%$ of students' responses referred to measure of average kinetic energy (category 3 ).

Table 1. Categories and some examples of the students' conceptions of temperature

\begin{tabular}{|c|c|c|}
\hline Category & Students' conceptions of temperature & $\% \mathrm{~N}$ \\
\hline 1 & $\begin{array}{l}\text { Temperature is a quantity for measuring hotness or coldness. } \\
\text { Examples } \\
\text { - It can tell us that objects are cold or hot. } \\
\text { - If temperature of object is high, this object is a hot object. }\end{array}$ & 29 \\
\hline 2 & $\begin{array}{l}\text { Temperature is a quantity for measuring the mount of heat. } \\
\text { Examples } \\
\text { - Temperature is a number that shows the mount of heat in objects } \\
\text { - Temperature shows about levels of heat in substances }\end{array}$ & 35 \\
\hline 3 & $\begin{array}{l}\text { Temperature is a quantity for measuring average kinetic energy of atoms. } \\
\text { Example } \\
\text { - If temperature of objects is high, average kinetic energy of particles of the } \\
\text { objects is high as well. }\end{array}$ & 1 \\
\hline 4 & $\begin{array}{l}\text { Temperature is indicated to state of matters. } \\
\text { Examples } \\
\text { - Temperature of substances can be indicated states of substances. } \\
\text { - Temperature is something that can change the state of substances }\end{array}$ & 7 \\
\hline 5 & $\begin{array}{l}\text { Temperature is indicated to state of atmosphere. } \\
\text { Example } \\
\text { - Temperature can be indexed to characteristic of atmosphere }\end{array}$ & 15 \\
\hline 6 & $\begin{array}{l}\text { Temperature is a form of energy that is inside of matters. } \\
\text { Examples } \\
\text { - It is hidden energy in the objects. } \\
\text { - temperature is a kind of energy that it is kept by the object. }\end{array}$ & 4 \\
\hline 7 & $\begin{array}{l}\text { Temperature is a quantity that can be measured using thermometers. } \\
\text { Examples } \\
\text { - It can be measured in }{ }^{\circ} \mathrm{C} \text { or }{ }^{\circ} \mathrm{F} \text { or } \mathrm{K} \text { units using a thermometer. } \\
\text { - We can use a thermometer to measure temperature. }\end{array}$ & 3 \\
\hline
\end{tabular}




\section{Analysis of the students' conceptions of heat}

Heat refers heat is a kind of energy, and heat will be transferred from the place to another if temperatures of objects are different. (MOE, 2001). Students' conceptions are presented in Table 2. They gave responses in different answers. Most students referred to main idea that heat is a kind of energy but there are different in some details.

The percentage of students in category 1 was the highest $(29 \%)$ followed by category $2(18 \%)$ and category $5(13 \%)$. There was only $4 \%$ of students who gave correct responses (category 7). There was only one student who gave response in category 10 and category 11.

Table 2. Categories and some examples of the students' conceptions of heat

\begin{tabular}{|c|c|c|}
\hline Category & Students' conceptions of heat & $\% \mathrm{~N}$ \\
\hline 1 & $\begin{array}{l}\text { Heat is a kind of energy. } \\
\text { Examples } \\
\text { - Heat is a type of energy. } \\
\text { - Heat is energy. }\end{array}$ & 29 \\
\hline 2 & $\begin{array}{l}\text { Heat is energy related to temperature. } \\
\text { Examples } \\
\text { - It can be used to rise temperature of objects. } \\
\text { - If there is rising of temperature, heat will occur. } \\
\text { - Heat is occurred from changing in temperature. }\end{array}$ & 18 \\
\hline 3 & $\begin{array}{l}\text { Heat is a kind of energy that emitted from objects. } \\
\text { Examples } \\
\text { - It is heat energy that emitted from objects to our so we will get } \\
\text { hot feel. } \\
\text { - it is energy that emitted from living things such as human }\end{array}$ & 8 \\
\hline 4 & $\begin{array}{l}\text { Heat is a kind of energy that can be transformed to other kinds } \\
\text { Example } \\
\text { - It is a type of energy that it can transformed from once type to } \\
\text { other types. }\end{array}$ & 2 \\
\hline 5 & $\begin{array}{l}\text { Heat is energy that is inside of matters and has effect to changes of state. } \\
\text { Examples } \\
\text { - It can be used to melt ice. } \\
\text { - It can melt solid objects. } \\
\text { - Heat is hot thing and it can be used to change states of matters. }\end{array}$ & 13 \\
\hline 6 & $\begin{array}{l}\text { Heat is something that is around, invisible but we can feel. } \\
\text { Example } \\
\text { - Something is invisible and hot and we can not touch it. }\end{array}$ & 5 \\
\hline 7 & $\begin{array}{l}\text { Heat is a kind of energy, and heat will be transferred from the place to } \\
\text { another if temperatures of objects are different. } \\
\text { Example } \\
\text { - Something is invisible and hot and we can not touch it. }\end{array}$ & 4 \\
\hline 8 & $\begin{array}{l}\text { Heat is something that relate to kinetic energy. } \\
\text { Examples } \\
\text { - It can be transferred between objects. } \\
\text { - It is a kind of energy that can be transferred. } \\
\text { - It is energy that transferred due to difference in temperature. }\end{array}$ & 0.5 \\
\hline 9 & Heat is occurred from oscillation of atoms. & 1 \\
\hline 10 & Heat can be generated to works. & 1 \\
\hline 11 & Heat is a quantity in physics. & 0.5 \\
\hline
\end{tabular}




\section{Analysis of the students' conceptions of latent heat}

Latent heat is the amount of energy in the form of heat released or absorbed by a substance during a change of phase without changing the temperature (MOE, 2001). Students' conceptions are presented in Table 3.

In category 1, students' responses stated that latent heat is a kind of energy related to changes of state. Students referred to changing of phases of objects that they did not think about temperature of objects. For students' responses in category 2, students referred to the mount of heat energy that is used in changes of state without changing temperature. Also they have known about changes of states without changing temperature. Most students referred that latent heat is a kind of energy inside of body of matters (category 3 ). They understood that latent heat is hidden energy inside of body of objects. For category 4, students stated that latent heat is shown to the mount of heat energy used in change of temperature without changing state. A 3\% of students responded that latent heat is a kind of energy (category 5).

The percentage of students' responses in category 3 was the highest $(35 \%)$ followed by category $1(32 \%)$ and category $2(13 \%)$. There was $14 \%$ of students have no response to the question.

Table 3. Categories and some examples of the students' conceptions of latent heat

\begin{tabular}{|c|c|c|}
\hline Category & Students' conceptions of latent heat & $\% \mathrm{~N}$ \\
\hline 1 & $\begin{array}{l}\text { Latent heat is a kind of energy related to changes of state. } \\
\text { Examples } \\
\text { - It relate to changes of state of matters. } \\
\text { - It is energy that is specific to states of matters. }\end{array}$ & 32 \\
\hline 2 & $\begin{array}{l}\text { Latent heat is the mount of heat energy that is used in changes of state } \\
\text { without changing temperature. } \\
\text { Examples } \\
\text { - It is heat energy to change states of objects without changing } \\
\text { temperature. } \\
\text { - It is the mount of heat energy used in changes of states without } \\
\text { changing temperature. }\end{array}$ & 13 \\
\hline 3 & $\begin{array}{l}\text { Latent heat is energy that is inside of matters. } \\
\text { Examples } \\
\text { - It is energy that is inside of matters. } \\
\text { - It is hidden energy that contain in the matters. }\end{array}$ & 35 \\
\hline 4 & $\begin{array}{l}\text { The mount of heat energy is used in change of temperature without } \\
\text { changing state. } \\
\text { Example } \\
\text { - It shows the mount of heat energy used in change of temperature } \\
\text { without changing state. }\end{array}$ & 3 \\
\hline 5 & $\begin{array}{l}\text { Latent heat is a kind of energy. } \\
\text { Example } \\
\text { It is a kind of energy that it is important. }\end{array}$ & 3 \\
\hline
\end{tabular}

\section{Analysis of the student s' conceptions of specific heat capacity}

Specific heat capacity is the measure of the amount of heat energy that is required to increase the temperature of one gram of a substance by one degree (MOE, 2001). Students' responses are classified into categories of conceptions as shown in Table 4. 
Students' conceptions in category 1, students referred to the mount of heat to increase the temperature of one gram of a substance. In category 2 shown that students' tendency to think about ability of heat capture of a substance and heat is contained inside a body. In category 3 , students stated that specific heat capacity has effect to change of temperature or change of phases. Students' responses in category 4 in referred to heat flow and students' responses in category 5 stated that specific heat capacity has effect to changes of phases. They understood that the great of value of specific heat capacity, the great in resistance to changes state.

The percentage of students' conceptions of specific heat capacity in category 2 was the highest (33\%) followed by category $3(24 \%)$ and category $1(8 \%)$.

Table 4. Categories some examples of the students' conceptions of specific heat capacity

\begin{tabular}{cccc}
\hline Category & \multicolumn{1}{c}{ Students' conceptions of specific heat capacity } & $\% \mathrm{~N}$ \\
\hline 1 & The amount of heat energy that is required to raise the temperature of one gram of a & 8 \\
substance by one degree. \\
Examples \\
- It is heat energy used in raise the temperature of one gram of object by one \\
degree.
\end{tabular}

\section{Analysis of the students' conceptions of thermal equilibrium}

Thermal equilibrium refers to a higher temperature object which is in contact with a lower temperature object will transfer heat to the lower temperature object. The objects will approach the same temperature, and in the absence of loss to other objects, they will then maintain a constant temperature. They are then said to be in thermal equilibrium (MOE, 2001).

Students' responses are presented in Table 5. Students' conceptions (5\%) in category 1, they understood that heat energy inside a body is constant if the mount of heat energy absorbed and emitted by a substance are equal. 
For category 2 of students' responses, most students (27\%) referred that there is no heat transfer if the mount of heat energy in two bodies are equal. Students (10\%) referred to temperature of objects and surrounding are the same as shown category 3. Students' understanding (19\%) in category 4 , there is no change of amount of heat that is contained inside a body. $3 \%$ of students responded that thermal equilibrium related to changes of state of substances (category 5). As seen from all categories of students' responses, students have separately responded into minor ideas about thermal equilibrium. They did not integrate those minor ideas.

The percentage of students' conceptions of specific heat capacity in category 2 was the highest (27\%) followed by category $4(19 \%)$ and category $3(10 \%)$.

Table 5. Categories and examples of the students' conceptions of thermal equilibrium

\begin{tabular}{|c|c|c|}
\hline Category & Students' conceptions of thermal equilibrium & $\% \mathrm{~N}$ \\
\hline 1 & $\begin{array}{l}\text { The amount of heat energy that be absorbed and emitted by matters are } \\
\text { equal. } \\
\text { Examples } \\
\text { - Objects emit and absorb equal amount of heat. } \\
\text { - There are receive and give heat that amount of heat are equal. }\end{array}$ & 5 \\
\hline 2 & $\begin{array}{l}\text { Situation occurred when a mount of heat energy of two objects are equal, } \\
\text { no heat transfer. } \\
\text { Examples } \\
\text { - It's state of equal amount of heat. } \\
\text { - There is no heat transfer between two objects. } \\
\text { - It is balance of heat energy, no more heat transfer. }\end{array}$ & 27 \\
\hline 3 & $\begin{array}{l}\text { Temperature of matters in the same surrounding are equal and equal to } \\
\text { temperature of surrounding. } \\
\text { Examples } \\
\text { - Temperatures of two objects are equal and equal to temperature } \\
\text { of its surrounding. } \\
\text { - Temperature of an object is the same at temperature of air. }\end{array}$ & 10 \\
\hline 4 & $\begin{array}{l}\text { Amount of heat energy is constant. } \\
\text { Examples } \\
\text { - It is state that amount of heat is constant. } \\
\text { - amount of heat does not change }\end{array}$ & 19 \\
\hline 5 & $\begin{array}{l}\text { Relate to changes of state. } \\
\text { Examples } \\
\text { - It is energy used to change states of objects. } \\
\text { - Energy of an object is constant when its state is change. }\end{array}$ & 3 \\
\hline
\end{tabular}

\section{Analysis of the students' conceptions about heat conduction}

The results from the second open-ended question are shown in Table 7 and Table 8. One of the main aims of this study was to determine students' misconceptions about the heat conduction in metal and wood so their explanations had to be examined in detail, especially in two categories: Partial Understanding and Specific Misconceptions. 
Data collected from the question were analyzed and classified into different levels of understanding. To assess students' explanations in the questions, a five-item criterion (Costu \& Ayas, 2005; Gönen \& Kocakaya, 2010) was used. These criteria are shown in Table 6.

Table 6. The criteria for the classification of students' responses in the second open-ended question

\begin{tabular}{ccc}
\hline Levels of understanding & \multicolumn{1}{c}{ Criteria for the classification of student responses } \\
\hline - Sound understanding & $\begin{array}{l}\text { Responses that include all components or some of the } \\
\text { scientifically accepted responses. }\end{array}$ \\
- Partial understanding & $\begin{array}{l}\text { Responses that include at least one of the components of the } \\
\text { acceptable ideas and that show understanding of concepts } \\
\text { but that may also contain a kind of misconception. } \\
\text { Responses that include descriptive, incorrect or illogical } \\
\text { information. }\end{array}$ \\
- Specific misconception & $\begin{array}{l}\text { Repeats a part of, or full question; irrelevant or uncodable } \\
\text { responses. 'I don't understand' } \\
\text { 'No answer'; 'I don't know'; 'I have no idea' }\end{array}$ \\
\hline
\end{tabular}

The question 2 is about comparing the heat conduction in metal and wood. Preknowledge that students must know include:

(1) Heat conduction in metal and wood are different and.

(2) Heat conduction in metal and wood depend on the value of thermal conductivity of each matter.

Students' understandings of the heat conduction in metal and wood were evaluated according to the scheme listed in Table 7. Students' responses to the question were examined in detail in order to determine the levels of students' understandings according to the scheme listed in Table 8.

Table 7. Percent of student responses for the second open-ended question

\begin{tabular}{cccc}
\hline $\begin{array}{c}\text { metal colder than } \\
\text { wood }(\%)\end{array}$ & $\begin{array}{c}\text { metal hotter than wood } \\
(\%)\end{array}$ & $\begin{array}{c}\text { metal equal to } \\
\text { wood }(\%)\end{array}$ & $\begin{array}{c}\text { No responses } \\
(\%)\end{array}$ \\
\hline 62 & 21 & 1 & 16 \\
\hline
\end{tabular}

As seen from Table 7, The percentages of the students' responses in 'metal colder than wood' category, 'metal hotter than wood' category, 'metal equal to wood' category and 'no response' category are 62, 21, 1 and 16\% respectively. Most students stated that a piece of metal colder than a piece of wood when they touch it, but couldn't give satisfactory explanations. 
Table 8. Percentages of the students who gave responses in different levels of understanding in 'metal colder than wood' category

\begin{tabular}{llc}
\hline UL & Examples & $\% \mathrm{~N}$ \\
\hline SU & - Metal colder than wood because heat energy can be transferred from our hands & \\
& to a piece of metal greater than to a piece of wood. & 28 \\
& - Metal colder than wood because particles in metal are more closely than in \\
& wood so that it can be transferred heat from our hands to it greater than a piece \\
& of wood.
\end{tabular}

PU - Metal colder than wood because heat energy can be transferred by a piece of metal greater than by a piece of wood.

- Metal colder than wood because ability of heat conduction of metal and wood are different.

- Metal colder than wood because the metal is heat conductor.

SM - Metal colder than wood because the coldness can be absorbed by the metal greater than the wood.

- Metal colder than wood because heat energy can be transferred by the metal less than the wood but the coldness can be absorbed by the metal greater than the wood.

- Metal colder than wood because the hotness can be slowly absorbed by the metal.

- Metal colder than wood because the hotness can be less transferred to our hands by the metal than the wood.

NU - Metal colder than wood because the specific heat capacity of the metal greater than the wood.

- Metal colder than wood because the density of the metal greater than the wood.

- Metal colder than wood because atoms of the metal can move.

- Metal colder than wood the value of the latent heat of the metal is less than of the wood.

- Metal colder than wood melting point of the metal higher than the wood.

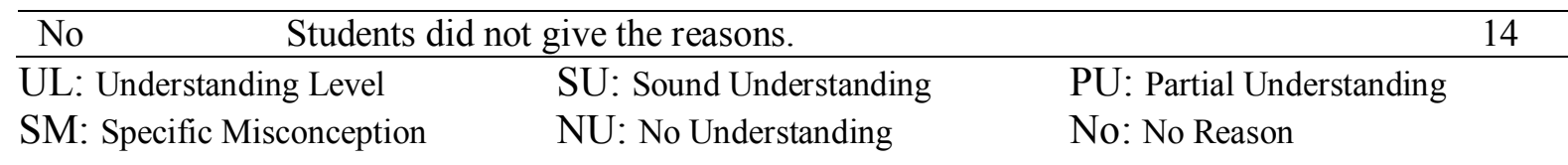

The study focused on only students' responses in 'metal colder than wood' category. In this category, students gave responses in the correct category but they did not apply the correct reason to explain their answers. It is important to classify the level of their understandings by considering their reasons. As seen from Table 8, the percentages of the students, who gave responses in 'metal colder than wood' category, classified as in 'sound understanding' category, 'partial understanding' category, 'specific misconception' category, 'no understanding' category, and 'no reason' category are $28 \%, 26 \%, 13 \%, 19 \%$ and 14\% respectively. Moreover, some students gave responses that showed sound understanding or partial understanding of the concept but also stated some specific misconception and no understanding. 
The question 2 used to probe students' understandings was based on a daily situation or daily experience. Researchers then expected that students may use their least efforts to answer the correct answer for the first part (daily life part) of the question and spent more thinking time to answer the second part (scientific reason part) of the question. If the students understood the concept of the heat conduction, they should clearly explain the mechanism. But the results showed otherwise. From the Table 7, 62 percents of students answered "metal colder than wood" category offered encouraging result. However, the percentage of the reasonable explanation accompanying with the correct answer did not go the same way (see table 8). There were a number of students who were unable to explain the correct reason for their answers. The Table 8 shows clearly that percentages of students who had misconceptions, not understood and no reason for their answers are significant.

The data from students' responses show that students have different understandings of the concept of the heat conduction in metal and wood. Most students have misconception or no understanding. Most students did not give satisfactory reasons to the open-ended question because they were unable to explain the reason correctly.

\section{Conclusions and Implications}

This study, it is to investigate and classify students' conceptions of temperature, heat, latent heat, specific heat capacity, thermal equilibrium, and heat conduction.

Most students did not give satisfactory answers to the open-ended questions because they were unable to explain definitions and scientific reasons correctly. By applying a correct reason they have to apply, analyze or synthesize the knowledge.

The results from the question1, students gave responses to the question in different type of understanding. Although, students have been taught in high schools, most students did not give answers correctly in each word. They gave answers that were classified into several categories of conception.

The result from the question 2 can be used to indicate that most students are lack of a basic concept on the heat conduction even though they had been taught already in the secondary level. This is hardly acceptable that even the correct responses to the basic question on the heat conduction between metal and wood were as poor as show in the table 7. This is harder to accept the results that most students who answered correctly could not provide sound reasons with their responses. In fact, the answer to the first part of the question should be easy because it concerns a daily life situation while secondary need a physics background in the mechanism of the heat conduction in explanation. By giving both correct answers, students should be equipped with both fact and accompanying scientific reason. For the scientific reason part, the classroom should mainly be the source to provide for the students. The way to provide should not be one way talk because the information given is easily forgotten. Students act only as passive listeners. They are told almost everything. The most appropriate method is two way talking or active learning. Teachers acting as facilitator only encourage students to think for themselves and allow them to participate in the learning process and find out what really happen on their own based on appropriate information provided. This means that no complete information is given beforehand. Therefore, they should be able develop scientific thinking to explain any situation they encounter (Knight, 2004).

The proposed study involves the determination of the students learning improvement and the effect of instruction method on students learning improvement. Most Thai high school students have learned based on the 2001 National Curricula in Thailand (the curricula has been reformed with the intent to improve students' knowledge, thinking process, inquiry 
thinking skill, problem solving skill, ability of scientific communication, ability of application and scientific attitude) but they were taught using traditional teaching method. Although most instructors have more scientific knowledge, they have a lake of active teaching skills. In addition, experiments about thermal physics are not active laboratories. The direction of the experiments is cookbook that it cannot be used to improve students' scientific skills.

This indicates that their understandings still need to be improved. The results showed that terribly effect of instruction method on students learning improvement. Further, some active learning methods will be used to help students to improve their understandings.

\section{References}

Abraham, M. R., Grzybowski, E. B., Renner, J. W., \& Marek, E. A. (1992). Understanding and misunderstanding of eight graders of five chemistry concepts found in textbooks. Journal of Research in Science Teaching, 29(2), 105-120.

Abraham, M. R., Williamson, V. M., \& Westbrook, S. L. (1994). A cross-age study of the understanding of five chemistry concepts. Journal of Research in Science Teaching, $31(2), 147-165$.

Ali, E. (2002). Effects of conceptual assignments and conceptual change discussions on students' misconceptions and achievement regarding force and motion. Journal of Research in Science Teaching, 39(10), 1001-1015.

Ayas, A. (1993). A study of teachers' and students' view of the upper secondary curriculum and students' understanding of introductory chemistry concepts in the east black-sea region of Turkey. Unpublished Doctoral Dissertation. UK: University of Southampton.

Confrey, J. (1990). A review of research on student conceptions in mathematics, science, and programming. In C. Cazden (Ed.), Review of Research in Education, 16 (pp. 3-56). Washington: American Educational Research Association.

Carlton, K. (2000). Teaching about heat and Temperature. Physics Education, 35(2), 101.

Costu, B. \& Ayas, A. (2005). Evaporation in different liquids: secondary students' conceptions. Research in Science \& Technological Education, 20(1), 75-97.

Duit, R., \& Treagust, D. F. (1998). Learning in Science: From behaviorism towards social constructivism and beyond. In B. J. Fraser, K. G. Tobin. (Eds.), International Handbook of Science Education (pp. 3-25). Dordrecht, The Netherlands: Kluwer Academic Press.

Evaluation Instruments. (September 2010). Retrieved on September 17, 2010, From http://modeling.asu.edu/R\&E/Research.html.

Geraedts, C. L., \& Boersma, K. T. (2006). Reinventing natural selection. International Journal of Science Education, 28(8), 843-870.

Gönen, S., \& Kocakaya, S. (2010). A cross-age study: A Cross-Age Study on the Understanding of Heat and Temperature. Eurasian Journal of Physics and Chemistry Education, 2(1):1-15.

Harrison, A. G., Grayson, D. J., \& Treagust, D. F (1999). Investigating a grade 11 student's evolving conceptions of heat and temperature. Journal of Research in Science Teaching, 36(1), 55-87. 
Jara-Guerrero, S. (1993). Misconceptions on heat and temperature. Proceedings of the Third International Seminar on Misconceptions and Educational Strategies in Science and Mathematics, Misconceptions Trust, Cornell University, Ithaca, NY, USA.

Jasien, P. G., \& Oberem, G. E. (2002). Understanding of elementary concepts in heat and temperature among college students and K-12 teachers. Journal of Chemical Education, 79(7), 889-895.

Johnstone, A. H., Macdonald, J. J., \& Webb. G. (1977). Misconceptions in school thermodynamics. Physics Education, 12(4), 248-251.

Knight, R. D. (2004). Five Easy Lessons Strategies for Successful Physics Teaching. San Francisco, USA: Addison Wesley Press.

Lewis, E. L., \& Linn, M. C. (2003). Heat energy and temperature concepts of adolescents, adults, and experts: Implications for curricular improvements, Journal of Research in Science Teaching, 40(S1), S155-S175.

Luera, G. R., Otto, C. A., \& Zitzewitz, P. W. (2006). Use of the Thermal Concept Evaluation to Focus Instruction. The Physics Teacher, 44(3), 162-166.

McDermott, L.C., \& Redish, E.F. (1999). RL-PR1: Resource Letter on Physics Education Research, American Journal of Physics, 67(9), 755-767.

Ministry Of Education [MOE] (2001) The Curriculum A. D. (2001) (Bangkok: the Institute for the Promotion of Teaching Science and Technology, Ministry of Education).

Niaz, M. (2006). Can the study of thermochemistry facilitate students' differentiation between heat energy and temperature?. Journal of Science Education and Technology, 15(3), 269-276.

Paik, S. H., Cho, B. K., \& Go, Y. M. (2007). Korean 4- to 11-year-old student conceptions of heat and temperature. Journal of Research in Science Teaching, 44(2), 284-302.

Sozbilir, M. (2003). A review of selected literature on students' misconceptions of heat and temperature, Boğaziçi University Journal of Education, 20(1), 25-41.

Thomas, P. L., \& Schwenz, R. W. (1998). College physical chemistry students'

conceptions of equilibrium and fundamental thermodynamics. Journal of Research in Science Teaching, 35(10), 1151-1160.

White, R., \& Gunstone, R. (1992). Probing understanding. London: Falmer Press.

Yeo, S., \& Zadnik, M. (2001). Introductory thermal concept evaluation: assessing students' understanding. Physics Teacher, 39(8), 496-504. 